\title{
O Olhar de Crianças do CAPSi sobre as Relações do Cuidar e do Brincar
}

\author{
Eloína Ariana Ribeiro Damasceno Silva ${ }^{1}$ \\ Maria Iracema de Sousa Araújo \\ Marcelo Silva de Souza Ribeiro \\ Melina de Carvalho Pereira \\ Universidade Federal do Vale do São Francisco, Petrolina, PE, Brasil
}

\begin{abstract}
Resumo
Este estudo buscou compreender as relações do cuidar e do brincar em um Centro de Atenção Psicossocial Infantil (CAPSi) do Vale do São Francisco na perspectiva das crianças usuárias. Tendo como orientação a multirreferencialidade metodológica, que concebe a integração de perspectivas epistemológicas da pesquisa, esta investigação baseou-se na fenomenologia e inspirou-se na etnografia. Treze crianças, com idade entre 7 a 11 anos, que frequentavam a instituição semanalmente, participaram da pesquisa que resultou nesse relato. Os instrumentos utilizados para coleta de dados foram: observação via diário de campo e atividades lúdicas (brincadeiras, entrevistas informais, recursos fotográficos e massa de modelar). Os dados foram analisados a partir da técnica de triangulação, que visa cruzar as informações, conteúdos e temas, apreendendo possíveis sentidos e significados. Por fim, através da redução fenomenológica, os temas emergentes foram identificados e organizados em categorias nomeadas como: $\mathrm{O}$ cuidado como comida/ necessidades básicas; O cuidado como afeto; Retribuindo o cuidado; Ambiência: fator de cuidado?; CAPSi como lugar de brincar; Prazer e envolvimento com o lúdico. Os resultados contribuíram para os estudos na área de saúde mental em geral, fomentando as discussões que valorizam o protagonismo da criança através de um trabalho dinâmico e flexível.
\end{abstract}

Palavras-chave: Crianças, brincar, cuidar, CAPSi, Fenomenologia.

\section{The Perspective of Children Attending CAPSi on the Relationship between Care and Play}

\begin{abstract}
This study sought to understand the relationship between care and play in a Children's Psychosocial Care Center (CAPSi as per its acronym in Portuguese) in the São Francisco Valley area from the perspective of child users. Using methodological multireferentiality as a reference, which allows the integration of epistemological research perspectives, this study was based on phenomenology and was inspired by ethnography. Thirteen children from 7 to 11 years of age, and attending the institution weekly, participated in the research, which resulted in this report. The instruments used were: observation via field diaries and play activities (games, informal interviews, photography and, play dough). Data was analyzed using the triangulation technique, which aims to cross information, content and themes, extracting possible senses and meanings. Finally, phenomenological reduction allowed the identification of emerging themes, which were organized in categories named as: Care as food / basic necessities; Care
\end{abstract}

Endereço para correspondência: Av. José de Sá Maniçoba, s/n - Centro, Petrolina, PE, Brasil 56304-917 (Colegiado Acadêmico de Psicologia). Fone (+55) 87 2101-6868. 
and affection; Reciprocating care; Ambience: is it a care factor?; CAPSi as a place for play; Pleasure and involvement with play. Results contributed to studies on mental health in general, also promoting further discussions, which can value the child's protagonism through dynamic and flexible work.

Keywords: Children, play, care, CAPSi, Phenomenology.

\section{Una Perspectiva de los Niños del CAPSi sobre las Relaciones entre el Cuidar y el Juego}

\section{Resumen}

Este estudio buscó comprender las relaciones del cuidar y el jugar en un Centro de Atención Psicosocial Infantil (CAPSi) del Valle del San Francisco en la perspectiva de los niños usuarios. Teniendo como orientación la multirreferencialidad metodológica, que concibe la integración de perspectivas epistemológicas de la investigación, este estudio se basó en la fenomenología y se inspiró en la etnografía. Trece niños, con edad entre 7 y 11 años, que frecuentaban la institución semanalmente, participaron de la investigación. Los instrumentos utilizados para colectar datos fueron: observación via diario de campo y actividades lúdicas (juegos, entrevistas informales, recursos fotográficos y plastilina). Los datos fueron analizados utilizando técnica de triangulación, que visa cruzar las informaciones, contenidos y temas, aprehendiendo posibles sentidos y significados. Por fin, a través de la reducción fenomenológica, los temas emergentes fueron identificados y organizados en categorías nominadas como: El cuidado como comida/ necesidades básicas; El cuidado como afecto; Retribuyendo el cuidado; Ambiente ¿factor de cuidado?; CAPSi como lugar de jugar; Placer y envolvimiento con lo lúdico. Los resultados contribuirán para los estudios en el área de salud mental, fomentando las discusiones que valoran el protagonismo del niño a través de un trabajo dinámico y flexible.

Palabras clave: Niños, jugar, cuidar, CAPSi, Fenomenología.

Ao abordar a temática da infância dentro do contexto de saúde mental, faz-se necessário debruçar-se sobre a história. Isso significa reconhecer a construção social da infância e, juntamente com ela, lançar um novo olhar para a conquista de direitos, que perpassam pela educação, assistência e saúde. Essa concepção de infầncia reverbera atualmente no desafio de dar continuidade às ações que valorizem a criança enquanto sujeito e que priorizem atitudes condizentes nos serviços de atendimento em geral.

Parte-se do consenso de que nem sempre o sentimento de infância existiu, embora a criança em todos os tempos dependa do cuidado de outro, sendo incapaz de desenvolver-se sozinha (Rossetti-Ferreira, Amorim \& Silva, 2004; Vygotsky, 1984; Wallon, 1959/1986). Compreende-se que, na história ocidental, antes da modernidade, não havia distinção entre o mundo adulto e o mundo infantil. Ariès (1914/2011), em seus estudos sobre a construção social da in- fância e da família, relata que, à medida que a criança era capaz de realizar atividades sem auxílio da mãe ou ama, era introduzida na sociedade, de maneira que realizava os mesmos afazeres e responsabilidades adultas, inclusive, vestindo-se de modo semelhante.

A própria palavra infância, que vem do latim infantia ou enfante, significando aquele que não fala, que ainda não foi alcançado pela linguagem, remete ao modo como as crianças eram criadas: desconsideradas em suas especificidades e sem valor para sociedade da época. A criança era vista como propriedade do adulto; só passava a existir quando podia se misturar e participar da vida adulta (Ariès, 1914/2011; Sarmento, 2005).

Houve um longo processo de construção de saberes e confronto de paradigmas para que esta criança, que anteriormente não era considerada até passar pelos testes de sobrevivência e poder ser produtiva, começasse a ser percebida e apreendida pelo olhar disciplinador das instituições 
família, escola e religião, como também da medicina, com a intenção de estabelecer a ordem, preparando, classificando e ditando modelos de desenvolvimento sadios e inadequados, aptos e inaptos para a sociedade em vigor (Ribeiro, 2006).

De acordo com Vorcaro (2011, p. 220), "a infância tornou-se objeto de disputa de poderes". Sobre isso, Foucault (2006) pontua que:

a vigilância da criança tornou-se uma vigilância em forma de decisão sobre o normal e o anormal; começou-se a vigiar seu comportamento, seu caráter, sua sexualidade; e é então que vemos emergir toda essa psicologização da criança no interior da própria família. (p. 154)

Dessa forma, havia forte interesse na docilização dos corpos, adestramento e domínio dos instintos para que a população, seja de adultos ou crianças, compactuasse das normas civilizatórias (Foucault, 2000). Aqueles que fugiam do que era posto como regra sofriam as consequências através da segregação. Logo, o sentimento de infância como dócil, frágil e carente de cuidados não aconteceu da mesma maneira para todas as crianças, de modo que aquelas que viviam marcadas pela condição social e padrões de comportamentos diferenciados passaram a ser estigmatizadas de menores infratores, trazendo em si a ideia de periculosidade e associação com o patológico. Essas crianças também foram vítimas do grande enclausuramento e dos rótulos associados à marginalidade, sendo esquecidas por um bom tempo na história e tratadas de modo indiferente à sua condição de puerícia (Ribeiro, 2006).

No Brasil, somente com o amplo movimento de redemocratização das políticas é que surgem algumas tentativas de dar conta do cuidado que foi negado à criança ou realizado de forma inadequada (Ministério da Saúde, 2005). Um exemplo disso é a Constituição de 1988, que garante a condição de cidadã a crianças e adolescentes, e consequentemente, "o direito à vida, à saúde, à alimentação, à educação, ao lazer, à profissionalização, à cultura, à dignidade, ao respeito, à liberdade e à convivência familiar e comunitária, além de colocá-los a salvo de toda forma de ne- gligência, discriminação, exploração, violência, crueldade e opressão", conforme descrito no artigo 227 da Carta Magna (Constituição, 1988).

O Estatuto da Criança e do Adolescente (ECA), na promulgação da Lei n. ${ }^{\circ} 8.069$ (1990), também foi outra conquista que permitiu a visibilidade da situação infantojuvenil, negando a condição de criança como objeto, para a legitimação de criança e adolescente como sujeito de direitos, numa tentativa de assegurar o cuidado e a singularidade dessa fase.

Todos esses avanços obtidos em forma de lei foram essenciais para que as crianças e os adolescentes fossem inclusos, posteriormente, nas discussões dos serviços de saúde mental e fizessem parte das idealizações da Reforma Psiquiátrica, regulamentada em 2001 com a Lei Paulo Delgado (Lei n $\left.{ }^{\circ} 10.216,2001\right)$. Mas, somente com muita militância do movimento antimanicomial é que estes, finalmente, tiveram acesso aos modelos de atenção disponibilizados pelo Sistema Único de Saúde (SUS), principal responsável pela concretização dos dispositivos de saúde públicos que rompem com o modelo asilar hospitalocêntrico (Ministério da Saúde, 2005).

Assim, os CAPS - Centro de Atenção Psicossocial - surgem com a proposta de garantir uma assistência psiquiátrica hospitalar compatível com as normas do SUS, através de uma rede de cuidados que ofereça tratamento digno às pessoas com sofrimento mental, proporcionando a não ruptura dos laços sociais e assistindo o sujeito de forma integral. Igualmente,

os serviços de saúde mental infanto-juvenil, dentro da perspectiva que hoje rege as políticas de saúde mental no setor, devem assumir uma função social que extrapola o afazer meramente técnico do tratar, e que se traduz em ações, tais como acolher, escutar, cuidar, possibilitar ações emancipatórias, melhorar a qualidade de vida da pessoa portadora de sofrimento mental, tendo-a como um ser integral com direito à plena participação e inclusão em sua comunidade, partindo de uma rede de cuidados que leve em conta as singularidades de cada um e as construções que cada sujeito faz a partir de 
seu quadro. (Ministério da Saúde, 2005, p. 14).

Nesse contexto, um grande desafio ainda é reconhecer que a brincadeira perpassa o humano como uma necessidade, que se presentifica de diversas formas e em diferentes culturas, sendo um elemento universal carregado de diversidades (Bichara, Lordelo, Carvalho \& Otta, 2009; Huizinga, 2000). Segundo Carvalho, Pedrosa e Rossetti-Ferreira (2012, p. 203) a brincadeira "é condição propiciadora de saúde e de qualidade de vida em qualquer idade", portanto, uma prática de fundamental importância em ambientes de cuidado, como é o caso do CAPSi.

Para Huizinga (2000) o jogo é mais antigo do que a cultura; isso pode ser evidenciado pelo fato de os animais brincarem assim como os homens. Ele ainda discorre que o jogo/brincar pode ser considerado mais do que um fenômeno fisiológico ou um reflexo psicológico. Ele contém um determinado sentido, seja qual for o tipo de jogo. O jogo implica a presença de um elemento não material (sentimentos) em sua essência, já que nele está implícito um sentido.

Muitos autores como Bichara et al. (2009), Carvalho et al. (2012), Leontiev (1978), Piaget (1973), Rocha (2005), Vygotsky (1984) e Wallon (1966) enfatizam o jogo e a brincadeira como fundamentais para o desenvolvimento da criança, pois possibilitam a reprodução do mundo que lhes cerca, assim como desempenho de papéis exigidos pela sociedade. Ambos promovem o desenvolvimento da imaginação e da criatividade, destacando que a imaginação é importante para o conhecimento da realidade (Pacheco \& Garcez, 2012).

Costa, Cadore, Lewis e Perrone (2013), em um trabalho feito com oficinas terapêuticas de contos infantis em um CAPSi, relatam como resultado observável a mudança das crianças em relação à socialização e à possibilidade de simbolização. Cervo (2010) explica que a criança nesses espaços pode ser muitas coisas a depender da condição de possibilidade do momento; elas podem experimentar outros papéis, podendo ser criança-experimento, criança-resistência, criança-defesa, criança-rejeição, criança-potência e criança-invenção.
Assim, nota-se que a brincadeira se torna uma forma poderosa de cuidado nos serviços que atendem crianças. Afinal, se a base do cuidado humano é compreender como ajudar o outro a se desenvolver como ser humano, cuidar significa valorizar e ajudar a desenvolver capacidades. Sobre isso, a Rede Nacional Primeira Infância (RNPI, 2010) pontua que "o resgate da dimensão lúdica torna o adulto mais sensível aos processos de desenvolvimento da criança" (p. 52).

Para Boff $(2004$, p. 33) "cuidar é mais que um ato; é uma atitude. Portanto, abrange mais que um momento de atenção, de zelo e de desvelo. Representa uma atitude de ocupação, preocupação, de responsabilização e de envolvimento afetivo um com o outro". Diante disso, é importante compreender o cuidado de uma forma abrangente, podendo dizer que a todo o momento o ser humano está propício ao cuidar. Para o mesmo autor, "o cuidado como modo de ser, perpassa toda a existência humana e possui ressonâncias em diversas atitudes importantes" (p. 56).

Diante do que foi apresentado, observa-se que a proposta de atenção à saúde mental infantojuvenil é relativamente nova, tendo ainda inúmeros desafios a serem alcançados, tais como: a desmistificação da loucura, a abertura para os diferentes modos de infância, valorizando suas singularidades e formas de existência, bem como o fortalecimento de ações engajadas na emancipação desses sujeitos. Além disso, Ronchi e Avellar (2013) pontuam a importância de uma ambiência segura e adequada às necessidades das crianças.

Nesse estudo, considera-se que fenômenos instituídos socialmente possuem raízes complexas, levando certo tempo para criação e aceitação de novos modos de subjetivação. Portanto, o trabalho que originou este artigo partiu do reconhecimento da necessidade de estudos na área da infância que questionem e problematizem a condição atual da criança, permitindo seu protagonismo e a expressão das vozes que foram silenciadas durante grande parte da história (Oliveira, Muylaert, \& Reis, 2012), além de redimensionar os aspectos relacionados ao cuidado, garantindo a cada criança o direito a ser criança. 
O estudo teve como objetivo compreender as relações entre o cuidar e o brincar em um Centro de Atenção Psicossocial Infantil (CAPSi) do Vale do São Francisco na perspectiva das próprias crianças usuárias. Mais especificadamente, buscou-se identificar a concepção que as crianças usuárias do CAPSi possuem sobre o cuidar e o brincar; descrever como as crianças percebem o cuidado e a brincadeira no espaço/ambiente do CAPSi; e conhecer como as crianças veem o cuidado e a brincadeira dispensada pelos profissionais a elas.

\section{Método}

O presente relato de experiência envolve um estudo interpretativo que se baseia no pressuposto de que o conhecimento é uma atividade humana comprometida, um processo dinâmico, um movimento, em que não há uma busca de ajustamentos de verdades a realidades (Clareto, 2005).

Tendo como orientação a multirreferencialidade metodológica (Macedo, 2000), que concebe a integração de perspectivas epistemológicas da pesquisa, este trabalho teve como base metodológica a fenomenologia, da inspiração etnográfica (Corsaro, 1997/2011) e se utilizou da observação participante como estratégia de campo. A pesquisa foi ainda considerada implicativa, no sentido de contemplar os atores envolvidos como produtores de conhecimentos (Macedo, 2012).

Para Husserl, a fenomenologia é uma volta ao que foi vivido, ao que foi experienciado, o ponto de partida de todas as ciências. A preocupação da fenomenologia é com a descrição do fenômeno, retornando às coisas mesmas como elas se apresentam. Ou seja, levar em conta que, antes de uma realidade objetiva, há um sujeito que vivencia e que, antes da objetividade, há uma realidade pré-data e, anteriormente ao conhecimento, existe uma vida que o originou (Martins, Boemer, \& Ferraz, 1990).

\section{A Instituição}

A pesquisa foi realizada num Centro de Atenção Psicossocial Infantil (CAPSi) do Vale do São Francisco, que atende em média 150 usuários por mês. $\mathrm{O}$ dispositivo oferece serviço ambulatorial de atenção diária a crianças e adolescentes, dos 5 aos 17 anos, com transtornos mentais e transtornos decorrentes do uso abusivo de substâncias psicoativas, como álcool e outras drogas. Nesse serviço, a rotina seguida pelos usuários consiste em: acolhimento (brincadeira livre), atividade proposta pelos profissionais (como desenhos, pinturas, recortes e colagens) e lanche.

O CAPSi funciona, desde a fundação em 2010 , numa casa de moradia adaptada. As instalações físicas são compostas por uma sala de recepção, uma sala de coordenação, duas salas de atendimentos (os grupos de família e de crianças e adolescentes), uma cozinha, uma área de serviço, banheiros e área externa de entrada.

A equipe da instituição é formada pelos seguintes profissionais qualificados na área da saúde: 01 médico psiquiatra, 02 psicólogas (uma exercendo a função de coordenadora), 01 assistente social, 01 enfermeiro, 01 técnico de enfermagem, além do porteiro, auxiliares de serviços gerais, técnica administrativa e 02 estagiários de psicologia.

\section{Participantes}

Foram convidadas a participar da pesquisa as crianças usuárias do CAPSi de ambos os sexos, com idade entre 7 e 11 anos, que frequentam a instituição um turno por semana. Para fins de pesquisa, foram utilizados apenas os dados referentes a 13 crianças (10 meninos e 3 meninas), que são identificadas por nomes fictícios. Foram excluídas as crianças que frequentaram apenas um encontro durante o período em que as pesquisadoras estavam na instituição. A escolha desse público foi feita em razão da dinâmica do CAPSi, que se organiza em grupos etários, subdividindo-os em grupos menores nos turnos matutino e vespertino, de maneira que reforça a permanência da criança na escola.

A opção por essa faixa etária teve como fundamento o estágio de desenvolvimento em que estão esses participantes, quando já conseguem se diferenciar do outro, explorar mentalmente o espaço físico, se vincular com mais estabilida- 
de com os adultos e expressar sua afetividade, classificando e ordenando suas vivências, sem desvalorizar a brincadeira como fator essencial para sua aprendizagem (Galvão, 1995).

\section{Procedimentos}

A pesquisa está de acordo com as normas da Resolução no 466/12 do Conselho Nacional de Saúde (CNS), que regulamenta a pesquisa com seres humanos no Brasil. Foi submetida ao Comitê de Ética da universidade em que as pesquisadoras estão vinculadas e, após parecer favorável ( $\mathrm{N}^{\circ}$ 978.030), foi apresentado aos pais ou responsáveis pela criança o Termo de Consentimento Livre e Esclarecido (TCLE), com a intenção de expor os objetivos da pesquisa. Em seguida, as crianças também foram esclarecidas quanto aos objetivos e procedimentos, deixando-as livres para a decisão de participarem, com a apresentação do Termo de Assentimento. Por fim, a inserção em campo e a coleta de dados aconteceram em sete encontros semanais, perfazendo um total de 18 horas.

\section{Instrumentos}

\section{Observação}

A observação foi do tipo participante, processo no qual o pesquisador não é apenas espectador, mas parte integrante dos fenômenos observados (Richardson, 1999), permitindo uma vivência mais ampla e detalhada da realidade pesquisada. Segundo Queiroz, Vall, Souza e Vieira (2007, p. 281), a observação "consiste em colocar-se sob o ponto de vista do grupo pesquisado, com respeito, empatia e inserção a mais íntima possível”. Essa etapa caracterizou-se como uma forma das pesquisadoras estarem em campo e se relacionarem com os atores envolvidos, visando à construção de um ambiente facilitador e, teve ainda como foco perceber as formas e os momentos de cuidado, bem como as brincadeiras desenvolvidas na rotina de atividades das crianças usuárias do CAPSi.

A escrita dos diários de campo foi uma constante durante o processo de realização da pesquisa. Através deles, as pesquisadoras puderam remeter-se à experiência vivida, revisitando o que foi observado, o que foi desenvolvido e os sentidos atribuídos. Essas anotações foram fundamentais para análise de dados que ocorreu posteriormente à coleta. Para Minayo "é exatamente esse acervo de impressões e notas sobre as diferenciações entre falas, comportamentos e relações que podem tornar mais verdadeira a pesquisa de campo" (2007, p. 295).

\section{Atividades Lúdicas}

Após a criação de vínculo com as crianças, que ocorreu durante quatro encontros, foi dado início às atividades lúdicas. Nesse período, as pesquisadoras propunham as atividades. Para Pompéia e Sapienza (2004, p. 21): "Todas as coisas falam para o homem através da fala do homem. Mas a obra de arte apresenta um falar especial", assim, o objetivo dessas atividades foi permitir que as crianças se expressassem sobre o tema proposto.

Nesse momento, a Caixa Surpresa foi apresentada às crianças com o objetivo de trazer o atrativo do dia, sinalizando que haveria novidades. Dentre os atrativos utilizados estavam: buzina, óculos coloridos, massa de modelar caseira, brinquedo de bolas de sabão. Essa etapa contou também com várias brincadeiras, como por exemplo: vivo e morto; contação de história com movimentos; adivinhação das mímicas e dobraduras de papel. O uso da massa de modelar, dentre as atividades lúdicas, além da interação das crianças com as pesquisadoras, teve como objetivo permitir que os infantes apontassem o que tinha no CAPSi, sendo motivadas a modelarem aquilo que era mais relevante para elas no dispositivo. Outras atividades desenvolvidas nessa etapa foram: As entrevistas informais/rodas de conversas e o recurso fotográfico.

A finalidade das entrevistas informais foi explorar o conhecimento das crianças sobre o cuidar e o brincar. Para Gil (2008), a entrevista informal é uma técnica eficiente e relevante para a obtenção de dados em profundidade acerca do comportamento humano, não exigindo que a pessoa entrevistada saiba ler e escrever, também possibilitando a obtenção de maior número de respostas, oferecendo uma flexibilidade maior, pois o entrevistador pode esclarecer os signi- 
ficados das perguntas e adaptá-las ao nível de entendimento do entrevistado. As entrevistas/ conversas lúdicas foram constantes. No último encontro, a fim de dinamizar a entrevista, uma câmera foi confeccionada e um microfone de madeira pintado para uma atividade que consistia num Programa de entrevista na TV, na qual elas poderiam assumir o papel do filmador, do entrevistador e do entrevistado.

$\mathrm{O}$ recurso fotográfico teve $\mathrm{o}$ intuito de captar a percepção das crianças sobre o brincar e cuidar na instituição em questão. "A fotografia é um testemunho segundo um filtro cultural e ao mesmo tempo uma criação a partir de um visível fotográfico. Toda fotografia representa o testemunho de uma criação e sempre representará a criação de um testemunho" (Kossoy, 2001, p. 50). Mediante a entrega de uma câmera fotográfica, a criança era solicitada a fotografar o que ela mais gostava no CAPSi. As crianças saíam de duas em duas para tirarem as fotografias. Esse momento ocorreu em uma das atividades lúdicas.

\section{Análise dos Dados}

A análise fenomenológica inicia com uma descrição, uma circunstância vivida no cotidiano. $\mathrm{O}$ inquiridor obtém declarações sobre o que está ali diante dos seus olhos, assim como aparece. O que é descrito nos depoimentos é a presença do dado, não a sua existência. Nesse momento, torna-se importante a atitude fenomenológica por parte do pesquisador, que vai ao encontro da experiência com abertura, se despojando de qualquer pensamento predicativo, julgamentos e concepções de que possam causar interferência na sua abertura para a descrição do fenômeno. Ao trabalhar a descrição do fenômeno, busca-se a sua essência, o elemento invariante da experiência, assim como ele está situado no contexto (Sadala, 2004).

A redução fenomenológica é o meio fundamental para a descrição do fenômeno, já que põe em evidência só o essencial do fenômeno em estudo, fazendo uma análise individual das descrições na busca das convergências ou invariantes. Martins et al. (1990) propõem quatro momentos para a análise das descrições, sendo elas: leitura da descrição do início ao fim com a finalidade de buscar um sentido geral do que está descrito; releitura na busca de perceber as unidades de significado focalizando o fenômeno; apreciação do sentido contido nelas; e por fim, síntese das unidades de significado e sentido encontrados.

Assim, esse trabalho teve como fenômeno a maneira como as crianças se posicionaram nas vivências do CAPSi, sinalizando, através da brincadeira e do vínculo com alguns profissionais, o sentido que a instituição tem para suas vidas e como este está atrelado ao brincar e cuidar. A escolha dos instrumentos utilizados foi de fundamental importância para que as crianças se implicassem, revelando seus anseios e sentimentos que perpassam pela instituição.

Após a coleta dos dados e o registro dos mesmos, estes foram organizados por instrumentos: da observação via diário de campo e das atividades lúdicas (brincadeiras, fotografias, entrevistas e massa de modelar). Em seguida, os dados foram analisados com base na técnica de triangulação, que visa cruzar as informações, conteúdos e temas, apreendendo possíveis sentidos e significados. Por fim, foram identificados os temas emergentes (Paillé, 2012) que, nessa perspectiva, foi considerado tema aquilo que os participantes apontaram como sendo relevante. Os temas emergentes, via a redução fenomenológica, foram organizados de acordo com suas "visadas" (sentidos e significados), sendo eles: O Cuidado como Comida/ Necessidades Básicas; O Cuidado como Afeto; Retribuindo o Cuidado; Ambiência: Fator de Cuidado?; CAPSi como Lugar de Brincar; Prazer e Envolvimento com o Lúdico.

\section{Resultados}

\section{O Cuidado como Comida/ Necessida- des Básicas}

Através das entrevistas informais, as crianças tentaram expressar sua concepção de cuidado. Embora, a maioria não tenha conseguido descrever o que significava, souberam dar exemplos de como esse cuidado acontece. A família apareceu como a responsável por exercer essa função, quando uma criança disse que sua mãe 
cuida dele, dando-lhe banho, comida, roupa para vestir, botando-lhe para dormir e, ainda, comprando brinquedo (Afonso, 9 anos).

Nas fotografias, as cenas que remetem à cantina do CAPSi estiveram presentes nos registros de quase todas as crianças para falar sobre o que mais gostavam na instituição. Este fato também apareceu na modelagem da massa: alguns tipos de alimentos estiveram presentes, como pastéis, bolinhos e biscoitos. Uma criança exibiu um biscoito peta (comida regional) moldado, com a massinha e disse: "minha mãe faz assim e frita" (Marlon, 8 anos).

Ao retornar aos diários de campo, percebeu-se que a hora do lanche era sempre a mais esperada. Uma das crianças já chegava ao serviço perguntando: "Ei, que horas é o lanche?" (Ítalo, 10 anos), ou ainda pedindo comida em horário adverso "Ei, me dá uma laranja". Outra dizia que uma das coisas que mais gostava no CAPSi era o lanche: "Nescau e beiju" (Afonso, 9 anos). Episódios como esses colaboram para compreender que as crianças se sentiam cuidadas, já que, para elas, a alimentação aparece como primeiro item de cuidado.

\section{O Cuidado como Afeto}

Uma criança (Arthur, 11 anos) relatou que cuidado é carinho, atenção, compreensão e amor, identificando os vínculos afetivos como necessários para que alguém se sinta cuidado. Foi observado que aqueles profissionais que dedicam mais atenção às crianças, gastando seu tempo com elas, participando das brincadeiras e tentando diálogo, conseguem mais rapidamente estabelecer vínculo, de maneira que são incluídos também como cuidadores. Isso ocorreu inclusive com as pesquisadoras, devido ao tempo de permanência delas no espaço, mas, principalmente, através da condição de abertura e envolvimento com as crianças, fator possibilitado pelo modo de estar em campo, a observação participante.

Dentre os profissionais da instituição, durante o período de coleta, o porteiro foi aquele que esteve mais disponível ao cuidado, sendo ele quem recebia as crianças e, quem permanecia durante todo o horário do acolhimento brincando com elas de bola, luta e de girar, segurando pelo antebraço das crianças. Em um dos momentos de observação, uma menina (Lara, 9 anos) dançou com ele que, pacientemente, se entregou ao momento vivido por aquela criança. Algo frequente é a demonstração de afeto pelas crianças, seja através de abraços ou ao se pendurar em seu pescoço. Uma mãe relatou que a filha (Tereza, 8 anos) somente reconhece pelo nome esse funcionário no CAPSi.

O porteiro também era quem acolhia as queixas trazidas pelos pais e crianças, oferecendo inclusive escuta. Uma das crianças (Lara, 9 anos), ao se chatear na sala de atividades, correu até ele para desabafar e dizer o quanto estava cansada de desenhos, "Todo dia é só desenho, desenho!", disse ela em tom de desapontamento.

O porteiro era tão presente no cotidiano do CAPSi que, quando faltou ao serviço, sua ausência foi sentida por todos. Isso ocorreu durante a execução da pesquisa, quando este foi lembrado várias vezes. As crianças assim comentavam: "Cadê Joaquim? Ele não vem hoje?" No momento em que a campainha tocava, todos corriam para porta com muita alegria, como de costume, mas ouvia-se um deles dizer: "Será que é Joaquim?" (Miguel, 9 anos).

No registro fotográfico, quase todas as crianças fotografaram o porteiro, demonstrando ser ele um dos elementos de que eles mais gostam na instituição. Uma delas (Olavo, 8 anos) perguntou à pesquisadora: "Eu posso tirar de Joaquim?" Ela respondeu: "Você gosta dele?" A criança diz que sim e vai caminhando até onde ele se encontra, fazendo um pedido: "Joaquim, faz um legal ai!', sinalizando com o dedo polegar e, em seguida, tirando a foto.

Outros profissionais apareceram nas fotos, mas em menor número. Uma criança relatou que: "As pessoas do CAPSi são legais" (Arthur, 11 anos). Também foram incluídas nas fotografias as pesquisadoras, sendo uma forma de expressar o cuidado recebido nesse espaço de tempo. Percebeu-se que, ao longo do percurso de coleta, algumas crianças abraçavam as pesquisadoras na hora de irem embora. Os registros dos colegas é outro fator relevante, pontuando a importância da interação que existe entre eles. Quando um colega chega ao serviço, por exemplo, eles 
costumam se cumprimentar e, escutou-se, em um dos momentos observados, um deles dizendo: "Chegou o meu parceiro!" (Miguel, 9 anos). Ocorrências como essas fornecem a compreensão de que a construção dos vínculos é, para as crianças, um modo de demonstrar cuidado.

\section{Retribuindo Cuidado}

Ao retornar aos diários de campo, notou-se que durante o período de observação aconteceram alguns conflitos entre as crianças e quebra de material escolar. Contudo, no período em que as pesquisadoras realizaram as atividades lúdicas, os conflitos diminuíram. As crianças participaram ativamente das atividades, utilizando-se da criatividade, rejeitando o que não queriam naquele momento e propondo o que gostariam de realizar. Elas demonstraram respeito e cuidado com todos os objetos utilizados, sempre preocupados em manter a integridade dos materiais, tais como: papel, lápis de cor, giz de cera e outros, bem como guardar os objetos na caixa de surpresa ao terminar as atividades. No momento da fotografia, por exemplo, uma das crianças (Olavo, 8 anos) demonstrou sua preocupação em pegar na câmera fotográfica com as mãos sujas de farinha, devido à atividade desenvolvida anteriormente com a massa de modelar, pedindo auxílio da pesquisadora para limpá-las. Isso parece indicar que as crianças, à medida que se sentiram cuidadas, retribuíram esse cuidado através do zelo.

\section{Ambiência: Fator de Cuidado?}

Dentro da instituição, os espaços mais utilizados pelas crianças são a área externa, a recepção e a sala de atividades. É na área externa que as crianças ficam no primeiro momento, quando chegam e interagem com os colegas. Não há nenhum elemento/brinquedo nesse local, apenas cadeiras. É comum as crianças brincarem de bola nesse espaço e de brincadeiras turbulentas (lutas). Na sala de recepção, além das mesas, cadeiras e televisor, há um espaço pequeno, que anteriormente era uma área de sol e, agora, é usado para colocar brinquedos dentro de uma caixa de papelão. Embora os brinquedos se encontrem em um estado bastante desgastado, ain- da encantam essas crianças que pegam alguns ou partes deles, para brincar fora dali. A sala onde se realizam as atividades com as crianças não tem iluminação natural, o espaço é pequeno e frio (ar condicionado). A sala contém apenas um armário, uma mesa e cadeiras empilhadas, e, nas paredes, são expostas as produções das crianças.

$\mathrm{Na}$ entrevista informal, perceberam-se sentimentos ambivalentes de pertença e envolvimento com o serviço. Uma criança relata: " $E u$ gosto de tudo aqui. Dos brinquedos, das atividades. Em casa, eu não tenho brinquedos, tenho um irmão que só briga comigo" (Marlon, 8 anos) e, ainda, pontua com pesar o fato de sua mãe não o levar toda semana. Mas, há também crianças que chegam ao CAPSi demonstrando tristeza. Uma delas (Arthur, 11 anos), ao ser questionada o motivo, diz que não queria ter ido. Essa criança resiste à entrada na sala de atividades e diz que não quer participar, menciona em outro dia que não gosta de brincar na instituição porque lá não tem brinquedos.

As descrições acima suscitam a compreensão de que o CAPSi, sendo um lugar específico para crianças, carece ainda de investimentos em sua infraestrutura. $\mathrm{O}$ que poderia tornar esse ambiente aconchegante e estimulador para esse público?

\section{CAPSi como Lugar de Brincar}

A brincadeira ocupa o primeiro lugar na preferência das crianças como atividade desenvolvida no CAPSi, principalmente a bola. É também a primeira atividade que eles desenvolvem ao chegar à instituição, quando se dirigem imediatamente até a caixa dos brinquedos e interagem com os colegas e porteiro. Esse momento de brincadeira livre tem duração de aproximadamente uma hora, quando, em seguida, as crianças são direcionadas para sala de atividades.

Em um desses momentos livres, observou-se que uma criança, ao chegar à instituição, começou a brincar de carrinho. Após ir até a caixa de brinquedos, retirava dela os objetos e era constantemente reprendido pela mãe, que dizia para ele ficar quieto e guardar. Quando ele se distanciou da caixa, ela guardou todos os brinquedos. O menino retorna e procura um brinque- 
do tirando todos da caixa novamente, ele diz: " $E$ agora, mãe?" A mãe, pouco paciente, responde: "Você vai guardar tudinho, eu não vou guardar mais não..." Além da mãe, notou-se que um dos funcionários do serviço, volta e meia, organizava a caixa, empurrando-a para perto da parede e colocando os brinquedos que estavam fora para dentro.

A área de entrada é o local preferido das crianças, apesar de ser muito quente. Lá elas correm, brincam, inventam e reinventam com as poucas opções disponíveis no CAPSi, tendo em vista que os brinquedos já se encontram em um estado bastante desgastado. Nota-se que nesse espaço de tempo que seria o acolhimento, eles se sentem livres e soltam a imaginação e a criatividade. Um pedaço de um carro de brinquedo vira uma arma e é utilizado também como avião; crianças brincam de moço e bandido. $\mathrm{O}$ brinquedo criado vai ganhando novos significados conforme a necessidade do garoto.

\section{Prazer e Envolvimento com o Lúdico}

No período de observação, percebeu-se que as brincadeiras se restringiram ao primeiro momento, quando as crianças chegavam à instituição e aguardavam a entrada na sala de atividades. Contudo, mesmo no período mediado pelo profissional do serviço, as crianças encontram meios de driblarem a programação do dia, através da criatividade e posicionamento lúdico, a exemplo do dia em que o projetor multimídia estava montado para exibição de um vídeo e as crianças o utilizavam para fazer sombras de animais, uma produção rica e ativa, demonstrando como a brincadeira está intrínseca à cultura infantil.

As atividades lúdicas propostas pelas pesquisadoras ocorreram no momento destinado às atividades em sala, permitindo que as crianças continuassem tendo o período de brincadeira livre. Na primeira semana de atividades lúdicas desenvolvidas, uma das brincadeiras proposta, por nome "Vivo ou Morto", teve pouca aderência das crianças. Uma delas (Arthur, 11 anos), ao assistir os que brincavam, falou: "Vocês são bestas!" e permaneceu sentado no seu canto, apenas observando. No momento da contação da histó- ria com movimentos, a adesão foi total. Somente ao final, quando sentiram sede, é que ficaram dispersos, por conta do calor excessivo, já que essa atividade foi realizada na área externa. Aos poucos, foram voltando e retomando a brincadeira. Foi um momento de muito envolvimento e entrega, tanto que, quando eles foram consultados em que momento a história parou, relembraram rapidamente, permitindo a continuidade.

Logo após essa atividade, entrou em cena a "Caixa Surpresa" que trazia alguns objetos para a brincadeira da "Mímica". As crianças, sentadas no chão ao redor das pesquisadoras, quando viram a caixa, ficaram agitadas, encostando mais perto das pesquisadoras, querendo tocar na caixa. Algumas delas ficaram falantes e se expressavam com gritos e movimentos corporais. A caixa causou um impacto grande nas crianças, pois aguçou a curiosidade delas, além de extravasar suas emoções com o uso da buzina e objetos coloridos (óculos, pulseiras e enfeites) que havia dentro dela.

Houve a tentativa de realizar desenho com as crianças nesse dia, pedindo que desenhassem o que tinha no CAPSi, mas eles não aceitaram fazer os desenhos. Retornando aos registros do diário de campo, é possível apreender que, no período de observação, o uso de desenhos foi constante nas atividades desenvolvidas pelo serviço e que as crianças pareciam expressar certo saturamento. Diante da recusa das crianças, as pesquisadoras lançaram mão de dobraduras de papel para fechar as atividades do dia, tendo uma boa aceitação e participação deles.

Na segunda semana de atividades lúdicas, a caixa surpresa voltou a mediar o contato das pesquisadoras com as crianças. Ao perguntarem o que teria ali dentro, um deles (Afonso, 9 anos) respondeu sorrindo: "Brinquedo!" Todos, juntamente com ele, queriam abrir, tocar e explorar aquelas novidades. Ao verem que se tratava de uma grande quantidade de massa de modelar, ficaram extasiados. Foram disponibilizadas também tintas para que eles pintassem da cor que desejassem e farinha para a melhor modelagem. Não demorou muito para que houvesse tinta e farinha espalhadas, as crianças experimentavam as cores e criavam suas obras, se divertiam jun- 
tas. Algo bastante relevante foi o fato de não haver nesse dia conflito entre eles. A bola foi um elemento que apareceu em suas produções e, inclusive, tentaram utilizar de modo convencional, atirando-a na parede.

Nessa semana também foi realizado o registro fotográfico, que trouxe com maior frequência os elementos que na instituição remetem à infância e ao lúdico, tais como: mural e cartazes na parede, criações artísticas feitas pelas crianças e os locais onde ocorre a brincadeira livre. Tanto os cartazes quanto as criações das crianças possuem cores alegres e enfeitam o ambiente.

$\mathrm{Na}$ terceira e última semana das atividades lúdicas, uma das crianças ao ver as pesquisadoras foi logo perguntando: "Vai ter caixa surpresa?" (Luiza, 10 anos), apontando seu interesse em que houvesse algo diferente nesse dia. As pesquisadoras perguntaram o que era necessário para uma entrevista e elas responderam: "Filmadora, microfone...", então logo depois foram apresentados uma filmadora e um microfone, ambos de brinquedo, para que se desse início à brincadeira de entrevistar. Elas gritavam e todas queriam pegar e usar, havendo um movimento de interesse comum em todas elas, mas não teve conflito, de maneira que souberam compartilhar os objetos.

A brincadeira foi bastante proveitosa, as crianças entrevistaram, filmaram, dançaram e cantaram. Elas ouviam o que as outras diziam e até complementavam, respondendo às perguntas feitas. Houve também um momento de despedida, introduzido pela psicóloga do serviço. Ela indagou para as crianças o que as pesquisadoras fizeram lá e estas prontamente respondem: "brincaram". Depois ela pergunta: "O que vocês queriam que tivesse aqui?" e algumas crianças disseram simultaneamente: "brinquedo!'

Logo depois, um deles (Afonso, 9 anos) inseriu a psicóloga do serviço na brincadeira, oferecendo-lhe o microfone para que falasse, utilizando-o e adentrando no universo simbólico compartilhado naquele momento. Ao final, a Caixa Surpresa apareceu, trazendo para as crianças brinquedos de fazer bola de sabão. Eles se alegraram bastante e, imediatamente, começaram a fazê-las, vendo quem faria a maior e tentando pegá-las. Episódios como esses colaboram para o entendimento que, ao trabalhar com crianças, o lúdico é um grande aliado, proporcionando uma participação maior e sentimentos de satisfação e prazer.

\section{Discussão}

Os resultados obtidos no presente estudo sugerem que, para o universo infantil, o cuidado está muito atrelado a uma figura lúdica, sendo ambos, cuidado e brincadeira, indispensáveis para o desenvolvimento. Rossetti-Ferreira et al. (2004) relatam que a sobrevivência do bebê humano só é possível diante de uma rede de cuidado, estabelecida através da relação com o outro, que funciona como mediador para o mundo. Bichara et al. (2009) apresentam a brincadeira como uma maneira de a espécie humana se adaptar ao mundo, experimentando novos repertórios, desenvolvendo habilidades e estabelecendo relações sociais.

$\mathrm{O}$ vínculo estabelecido entre as crianças e o Joaquim é muito forte. Embora ele seja "apenas" o porteiro, as crianças o elegeram como o profissional de referência, e isso é evidente quando, diante de sua falta, o simples toque da campainha deixa-as eufóricas com a possibilidade da sua chegada. Ronchi e Avellar (2013), ao falar de uma ambiência adequada à promoção de saúde mental, enfatizam a importância da presença de uma equipe formada por diversos profissionais que transitam pelo serviço priorizando um trabalho integrado, bem como da relação estabelecida entre eles com os usuários e entre profissionais.

A preparação dos profissionais para trabalhar com crianças é algo que deve ser levado em consideração ao falar de profissionais de CAPSi, inclusive a RNPI (2010) traz que: “A formação dos profissionais que atuam diretamente com a criança precisa ser revista na perspectiva de ampliar e aprofundar sua base de conhecimentos, aperfeiçoar qualidades e habilidades e desenvolver sua prática" (p. 86). Nota-se que, em se tratando de uma instituição voltada para infância, é necessário que os profissionais estejam mais disponíveis para participarem do mundo do faz de conta, da criatividade, da imaginação, ou seja, da 
brincadeira. Esse convite é feito pelas próprias crianças do serviço, a exemplo de quando uma delas ofereceu o microfone à psicóloga do serviço, demonstrando querer que ela também participasse daquele momento de fantasia.

A instituição que recebe os participantes da pesquisa não contempla um ambiente seguro e adequado às necessidades das crianças por apresentar em suas instalações aspectos em dissonância com um ambiente promotor de saúde, tais como: área de entrada sem adereços infantis, espaço pequeno e quente; sala de atividade muito pequena, refrigerada e sem luz solar; poucos brinquedos, em sua maioria deteriorada, assim como poucas brincadeiras nas atividades programadas. Sobre isso, Ronchi e Avellar (2013) pontuam que, para garantir um lugar seguro e adequado às necessidades das crianças e adolescentes, é indispensável estar atento à disponibilidade dos objetos no espaço e ao manejo das atividades desenvolvidas nesses ambientes.

No que diz respeito à alimentação, as crianças sinalizam a importância de tê-la na instituição, inclusive identificando-a como um fator de cuidado. Isso também foi percebido nos estudos de Ronchi e Avellar (2013), que mencionam o lanche como sendo uma rotina no CAPSi, demonstrando ser esse uma motivação para frequentar o serviço.

A preocupação dos familiares e de alguns dos profissionais em manter tudo "organizado", como é o caso da caixa de brinquedos, suscita um poder disciplinar operando sobre as crianças, ainda que de maneira sutil, o que Michel Foucault denominou de fabricação de corpos dóceis. "É dócil um corpo que pode ser submetido, que pode ser utilizado, que pode ser transformado e aperfeiçoado" (2000, pp. 117-118). Enquanto o corpo da criança se modifica, modela, se torna hábil e obedece, talvez seu direito de ser criança e de viver sua infância da maneira desejada e reclamada por elas, que é brincando, está sendo roubado.

As crianças em questão se aventuraram a experimentar aquele novo que despontava a sua frente com as atividades propostas pelas pesquisadoras, mas também resistiram, e se defende- ram rejeitando o que não queriam. Em relação a isso, Cervo (2010) menciona que a cada encontro com as crianças abrem-se possibilidades de invenções e afetações, que exigem dos profissionais sensibilidade para intervir e acolher. Sendo o brincar também fundamental para reequilíbrio e reciclagem das emoções (Pacheco \& Garcez, 2012).

A brincadeira foi algo evidente em todos os momentos durante a realização da pesquisa, desde as brincadeiras livres que ocorrem no espaço de tempo destinado ao acolhimento quanto às dirigidas pelas pesquisadoras durante o horário destinado às atividades. Houve vários momentos de intensa entrega das crianças às atividades propostas em que não havia brechas para conflitos e desavenças, e sim socializar e dividir aqueles momentos com os colegas, diferentemente do que foi presenciado durante a observação, em que as crianças demonstravam descontentamento e conflitavam com os colegas. Será que inserindo a brincadeira variada como experiência contínua nos serviços infantis não haveria melhora na qualidade, participação e relações estabelecidas?

Pacheco e Garcez (2012) trazem que, através do jogo e do brincar, houve uma ampliação das possibilidades de interação, o aumento da autoestima, do sentimento de pertencimento e o compartilhamento de saberes. Portanto, o brincar é riquíssimo para o desenvolvimento físico, cognitivo, emocional e de valores culturais, bem como para o aumento das capacidades sociais e da convivência familiar das crianças (RNPI, 2010).

As pesquisadoras firmaram um vínculo sustentável com as crianças durante o período observacional, fato que se evidencia nas inúmeras vezes em que as crianças se dirigiam a elas para conversarem e brincarem, como também ao decidirem registrar a passagem das pesquisadoras pela instituição através da fotografia. Isso ocorreu também no trabalho realizado por Costa et al. (2013), no qual foram percebidas evoluções nas trocas interativas em grupo e na relação com as estagiárias, criando novos sentidos para as singularidades das crianças. 
A pesquisa com as crianças no CAPSi possibilitou um espaço de escuta, reconhecendo essas crianças como sujeitos de direitos, o que contribuiu para que elas também se implicassem nas atividades recorrendo à criatividade e à imaginação. A experiência vivenciada no CAPSi difere de estudos que, ao discutir essa temática envolvendo crianças e adolescentes, utilizam-se de testes e escalas que limitam a expressão e a espontaneidade desse público, restringindo sua construção enquanto sujeitos de vontade e desejos (Oliveira et al., 2012).

\section{Considerações Finais}

Diante dos resultados encontrados, percebe-se o quanto que, para a criança, o cuidar e o brincar são importantes e imbricados, configurando-se como suas necessidades básicas. Compreendendo que a dimensão de cuidado não se limita ao corpo, mas se amplia para uma gama de significações reais e simbólicas, que contribuem para novos modos de subjetivação, torna-se imprescindível que espaços destinados a cuidar de crianças, como é o caso do CAPSi, potencializem o brincar em seu espaço.

O brincar deve ser considerado de fundamental importância em todas as fases de vida e, para a criança, principalmente, o brincar deve ser considerado algo muito sério, essencial para elaboração de sentidos e construção do seu próprio universo, que para ela representa a realidade. As experiências vivenciadas nesse estudo mostraram o quanto o lúdico fez diferença na proposta de cuidado ofertada durante a coleta dos dados, sendo ele uma válvula libertadora das práticas engessadas e, impulsionador de sensibilidade, leveza, inventividade e plasticidade.

Dessa forma, ressalta-se a importância de permitir que essas crianças sejam protagonistas do seu processo, através de um trabalho dinâmico e flexível, que valorize a criatividade do lúdico e oferte cuidado de modo amplo, fortalecendo as relações e os vínculos, contribuindo para promoção da saúde mental. Para trabalhos futuros, sugere-se que outras pesquisas possam ser feitas em instituições similares, contemplando as crianças que as frequentam.

\section{Referências}

Ariès, P. (2011). História social da infância e da família (2. ed., D. Flaksman, Trad.). Rio de Janeiro, RJ: LCT. (Original publicado em 1914)

Bichara, I. D., Lordelo, E. R., Carvalho, A. M. A., \& Otta, E. (2009). Brincar ou brincar: Eis a questão, perspectiva da psicologia evolucionista sobre a brincadeira. In M. E. Yamamoto \& E. Otta (Eds.), Psicologia evolucionista (pp. 104113). Rio de Janeiro, RJ: Guanabara-Koogan.

Boff, L. (2004). Saber cuidar: Ética do Humano Compaixão pela Terra (10. ed.). Petrópolis, RJ: Vozes.

Carvalho, A. M. A., Pedrosa, M. I., \& Rossetti-Ferreira, M. C. (2012). Aprendendo com a criança de zero a seis anos. São Paulo, SP: Cortez.

Cervo, M. R. (2010). Entre doces e travessuras: A produção de infância no CAPSi (Dissertação de mestrado em Psicologia Social e Institucional, Universidade Federal do Rio Grande do Sul, Instituto de Psicologia, Porto Alegre, RS, Brasil). Recuperado em http://www.lume.ufrgs.br/ handle/10183/70030

Clareto, S. M. (2005). Etnografias e pesquisas interpretativas: Crises da modernidade e enfrentamentos de seus impactos. In II Simpósio Internacional de Pesquisa Qualitativa II SIPEQ, Anais Eletrônicos. Bauru, SP: Universidade Estadual Paulista "Júlio de Mesquita Filho". Recuperado em http://www.sepq.org.br/livros.htm

Constituição da República Federativa do Brasil. (1988). Brasília, DF: Senado Federal.

Corsaro, W. A. (2011). Sociologia da Infância (2. ed., L. G. R. Reis, Trad.). Porto Alegre, RS: Artmed. (Original publicado em 1997)

Costa, A. M., Cadore, C., Lewis, M. S. R., \& Perrone, C. M. (2013). Oficina terapêutica de contos infantis no CAPSi: Relato de uma experiência. Barbaroi, (38), 235-249. Recuperado em http:// pepsic.bvsalud.org/scielo.php?pid=S0104$-65782013000100013 \& \mathrm{script}=\mathrm{sci}$ arttext\&tlng=en

Foucault, M. (2000). Vigiar e punir (R. Ramalhete, Trad.). Rio de Janeiro, RJ: Vozes.

Foucault, M. (2006). O poder psiquiátrico. São Paulo, SP: Martins Fontes. 
Galvão, I. (1995). Henri Wallon: Uma concepção dialética do desenvolvimento infantil. Petrópolis, RJ: Vozes.

Gil, A. C. (2008). Métodos e técnicas de pesquisa social. São Paulo, SP: Atlas.

Huizinga, J. (2000). Natureza e significado do jogo como fenômeno cultural. In Homo Ludens: $O$ jogo como elemento da cultura (pp. 11-44). São Paulo, SP: Perspectiva.

Kossoy, B. (2001). Fotografia e história. São Paulo, SP: Ateliê Editorial.

Lei $n^{\circ}$ 10.216, de 6 de abril de 2001. (2001). Dispõe sobre a proteção e os direitos das pessoas portadoras de transtornos mentais e redireciona o modelo assistencial em saúde mental.

Lei $n^{\circ}$ 8.069, de 13 de julho de 1990. (1990). Dispõe sobre o Estatuto da Criança e do Adolescente e dá outras providências.

Leontiev, A. N. (1978). Actividad, conciencia y personalidad. Buenos Aires: Ciencias del Hombre.

Macedo, R. S. (2000). A etnopesquisa crítica e multirreferencial nas ciências humanas e na educação. Salvador, BA: Editora da Universidade Federal da Bahia.

Macedo, R. S. (2012). A etnopesquisa implicada. Pertinência, criação de saberes e afirmação. Brasília, DF: Liber livro.

Martins, J., Boemer, M. R., \& Ferraz, C. A. (1990). Fenomenologia como alternativa metodológica para pesquisa - Algumas considerações. Cadernos da Sociedade de Estudos e Pesquisa Qualitativos, 1(1), 33-47. Recuperado em https:// www.academia.edu/3804576/CADERNOS DA_SOCIEDADE_DE_ESTUDOS_E_PESQUISAS QUALITATIVOS Caderno 01

Minayo, M. C. S. (2007). O desafio do conhecimento: Pesquisa qualitativa em saúde. São Paulo, SP Hucitec.

Ministério da Saúde. (2005). Caminhos para uma política de saúde mental infanto-juvenil. Brasília, DF: Autor.

Oliveira, T. G. P., Muylaert, C. J., \& Reis, A. O. A. (2012). Crianças como sujeitos na pesquisa: Uma revisão integrativa. Psicologia Hospitalar, 10(2), 2-16.

Pacheco, F. P., \& Garcez, E. M. S. (2012). O jogo e o brincar: Uma ação estratégica na promoção da saúde mental. Revista de Saúde Pública de Santa Catarina, 5(1), 87-142.

Paillé, P. (2012). La méthodologie qualitative (3. ed.). Paris: Armand Colin.

Piaget, J. (1973). Problemas de Psicologia Genética. São Paulo, SP: Forense.

Pompéia, J. A., \& Sapienza, B. T. (2004). Na Presença do Sentido: Uma aproximação fenomenológica a questões existenciais básicas. São Paulo, SP: Paulus.

Queiroz, D. T., Vall, J., Souza, A. M. A., \& Vieira, N. F. C. (2007). Observação participante na pesquisa qualitativa: Conceitos e aplicações na área da saúde. Revista de Enfermagem (UERJ), 15(2), 276-283.

Rede Nacional Primeira Infância. (2010). Plano Nacional pela Primeira Infância. Brasília, DF: Autor.

Ribeiro, P. R. M. (2006). História da saúde mental infantil: A criança brasileira da Colônia à República Velha. Psicologia em Estudo, 11(1), 29-38.

Richardson, R. J. (1999). Pesquisa social: Métodos e técnicas. São Paulo, SP: Atlas.

Rocha, P. K. (2005). Brinquedo terapêutico e crianças institucionalizadas vitimas de violência: Propondo um modelo de cuidado de enfermagem (Dissertação de mestrado em Enfermagem, Universidade Federal de Santa Catarina, Florianópolis, SC, Brasil).

Ronchi, J. P., \& Avelar, L. Z. (2013). Ambiência na Atenção Psicossocial Infanto-Juvenil: Um estudo no CAPSi. Saúde e Sociedade, 22(4), 10451058.

Rossetti-Ferreira, M. C., Amorim, K. S., \& Silva, A. P. S. (2004). Rede de significações: Alguns conceitos básicos. In M. C. Rossetti-Ferreira, K. S. Amorim, A. P. Silva, \& A. M. A. Carvalho (Eds.), Rede de significações e o estudo do desenvolvimento humano (pp. 23-33). Porto Alegre, RS: Artmed.

Sadala, M. L. A. (2004). A fenomenologia como método para investigar a experiência vivida: Uma perspectiva do pensamento de Husserl e de Merleau-Ponty. In Seminário Internacional de Pesquisa e Estudos Qualitativos II SIPEQ, Anais Eletrônicos. Bauru, SP: Universidade Estadual Paulista "Júlio de Mesquita Filho". Recuperado 
em http://www.sepq.org.br/IIsipeq/anais/pdf/ gt1/12.pdf

Sarmento, M. J. (2005). Gerações e alteridade: Interrogações a partir da sociologia da infância. $E d u$ cação e Sociedade, 26(91), 361-378.

Vorcaro, A. (2011). O efeito bumerangue da classificação psicopatológica da infância. In A. Jerusalinsky \& S. Fendrik (Eds.), O livro negro da psicopatologia contemporânea (pp. 219-229). São Paulo, SP: Via Lettera.

Vygotsky, L. S. (1984). A formação social da mente. São Paulo, SP: Martins Fontes.
Wallon, H. (1966). Do acto ao pensamento: Ensaio de Psicologia Comparada. Lisboa: Portugália.

Wallon, H. (1986). Os meios, os grupos e a psicogênese da criança. In M. J. G. Werebe \& J. NadelBrulfert (Eds.), Henri Wallon (pp. 168-178). São Paulo, SP: Ática. (Original publicado em 1959)

Recebido: 07/12/2015

$1^{a}$ revisão: 09/04/2016

$2^{a}$ revisão: 08/07/2016 Aceite final: 20/08/2016 